\title{
Increases in Intracellular Zinc Enhance Proliferative Signaling as well as Mitochondrial and Endolysosomal Activity in Human Melanocytes
}

\author{
Emil Rudolf Kamil Rudolf \\ Department of Medical Biology and Genetics, Charles University, Faculty of Medicine in Hradec Kralove, \\ Hradec Kralove, Czech Republic
}

\section{Key Words}

Zinc $\cdot$ Melanocytes $\cdot$ Mitochondria $\cdot$ Lysosomes $\cdot$ Melanoma

\begin{abstract}
Background/Aims: Zinc $(\mathrm{Zn})$ is an important microelement required by skin cells for a variety of biological processes. The role of $\mathrm{Zn}$ in melanocyte proliferation and homeostasis has to date not been investigated. Methods: Human dermal melanocytes were isolated from patients and their proliferative activity determined along with both total and labile $\mathrm{Zn}$ content. Subsequently, changes in proliferation as well as in Zn content were determined upon exposure of the dermal melanocytes to external Zn. Further in-depth analyses were undertaken aimed at measuring the expression of proliferation-related proteins (determined by immunoblotting and densitometry), as well as changes in mitochondrial biogenesis and membrane potential (assessed by fluorescence-based cellometry) along with endolysosomal activity (determined by spectrofluorimetrically-measured elevation in fluorescence of lysosomal-aimed nonfluorescent substrate). Results: Human skin melanocytes accumulate externally added Zn, a process which dose-dependently enhances their injury or proliferative activity. Enhanced proliferation is accompanied by an increased expression of the proteins AKT3, ERK1/2, c-MYC and CYCD. In addition, Zn-enriched melanocytes exhibit enhanced mitochondrial biogenesis, with individual mitochondria possessing stabilized mitochondrial membrane potential as well as showing elevated ATP and superoxide levels. Moreover, upon external exposure, Zn enters lysosomes/melanosomes, the activity of which is stimulated along with the process of autophagy. Conclusion: The determination of the unique $\mathrm{Zn}$-dependent stimulation of melanocytes and in particular the enhancement of the cells' mitochondrial as well as lysosomal/ melanosomal activities may prove important in tracing the sequence of steps in the process of melanomagenesis.

(C) 2017 The Author(s)

Published by S. Karger AG, Basel
\end{abstract}

\section{Introduction}

Zinc $(\mathrm{Zn})$ is an essential component of eukaryotic cells, where it is involved in many vital processes including the stabilization of cell membranes, transcription, cellular signal 


\section{Cellular Physiology Cell Physiol Biochem 2017;43:1-16 \begin{tabular}{ll|l} 
DOI: 10.1159/000480306 24,2017 & $\begin{array}{l}\text { O } 2017 \text { The Author(s). Published by S. Karger AG, Basel } \\
\text { www.karger.com/cpb }\end{array}$
\end{tabular} \\ Rudolf/Rudolf: Intracellular Zinc Enhances the Activity of Human Melanocytes}

transduction and maintenance of optimal redox balance [1]. In addition to its catalytic, structural and information role, $\mathrm{Zn}$ also displays significant antioxidant properties. It stabilizes cell membrane structure, protects sulfhydryl-containing proteins and maintains optimal levels of metallothioneins, which are potent scavengers of intracellular reactive oxygen species (ROS) [2]. Although present in all body tissues and organs, individual cells differ in their ability to handle and store $\mathrm{Zn}$, with some being in higher need of Zn, e.g. in the prostate gland, nervous system, digestive epithelia, bone, liver as well as skin and its appendages [3]. $\mathrm{Zn}$ is acquired exclusively via external sources; given the importance of $\mathrm{Zn}$ for an organism and with respect to the varying needs of individual cells and tissues, cellular Zn homeostasis must remain under strict and constant control. Zn management typically involves a host of influx, efflux and chelation mechanisms, i.e. the $\mathrm{Zn}$ transporting network. This system consists of $24 \mathrm{Zn}$ transport proteins including the ZnT family of Zn transporters [4], the ZIP family of Zn transporters [5] and metallothioneins (MTs) [6]. Irrespective of the external environment, within the cell this network insures both the maintenance of adequate $\mathrm{Zn}$ levels as well as distribution of Zn to particular subcellular compartments, with only a minor pool of intracellular $\mathrm{Zn}$ remaining in free form and thus readily available for particular biological effects.

Accordingly, it has been well-documented that unscheduled fluctuations in intracellular Zn levels (mostly in free form) can be associated with a number of adverse effects both at the cellular as well as organismal levels. These fluctuations lead to several known pathologies such as impaired immunity [7], respiratory deficiencies [8], defective growth and wound repair [9], decline in sensory acuity as well as neurodegeneration [10] and development of neoplasia [11]. At present several examples of human neoplasias have been shown in which $\mathrm{Zn}$ homeostasis has become compromised, thereby leading to an accumulation or a loss of intracellular Zn stores. These cases have been related to the incidence of several types of cancer, including in the prostate, breast, pancreas, lung and colorectal region [12].

Skin melanoma is a type of solid tumor with worldwide increasing incidence. Its leading characteristics include a heterogeneous genetic background and high mortality rates. Another feature of this skin cancer is the functional plasticity of cells, which invariably present an aggressive and invasive phenotype associated with developed chemoresistance [13]. Numerous hallmarks of melanoma have been established, including hyperactivation in the BRAF-MEK signaling cascade along with mutations in NRAS, KIT and ERBB4 genes as well as selected epigenetic changes [14]. Still, the sequence of steps in these processes remains unclear as well as which of these are concrete mechanisms contributing to the malignant conversion of skin melanocytes. Here we show for the first time that increases of $\mathrm{Zn}$ levels in normal human melanocytes via the selective cultivation of these cells in Zn-enriched cultivation media lead to changes in the proliferative signaling of the cells, enhanced mitochondrial biogenesis, as well as activity associated with increased production of both ATP and reactive oxygen species (ROS). Moreover, Zn-enriched cells accumulate Zn in lysosomes and melanosomes, with subsequently upregulated endolysosomal pathway activity and concomitantly enhanced autophagy. Taken together, these changes suggest that elevated intracellular $\mathrm{Zn}$ levels in melanocytes may contribute to enhanced proliferative signaling as well as to sustained and increased activity of selected subcellular compartments, with a possible influence on the long-term stability of these cells.

\section{Materials and Methods}

Cells

Human primary melanocytes MEL (passages 15-20) were isolated from patients undergoing skin surgery at the University Hospital Hradec Králové. The study was approved beforehand by the hospital ethics committee and in all cases tissues were obtained from subjects following informed consent.

Obtained skin specimens were rinsed in 70\% ethanol, then in PBS and after removing fat and subcutaneous tissue they were cut into small pieces $\left(3 \times 3 \mathrm{~mm}^{2}\right)$. These were transferred into test tubes 


\section{Cellular Physiology Cell Physiol Biochem 2017;43:1-16 \begin{tabular}{cl|l} 
DOI: 10.1159/000480306 & O 2017 The Author(s). Published by S. Karger AG, Basel \\
www.karger.com/cpb
\end{tabular} \\ Rudolf/Rudolf: Intracellular Zinc Enhances the Activity of Human Melanocytes}

with Dispase II and incubated at $4^{\circ} \mathrm{C}$ for $24 \mathrm{~h}$. The next day the tissues were transferred to Petri dishes and their epidermis removed using a forceps and scalpel blade. Thereafter, a drop of $\mathrm{Ca}^{2+}, \mathrm{Mg}^{2+}$-free PBS was added and the epidermal sheets were minced with a scalpel blade. The resulting mixture was transferred to a centrifuge tube containing $0.5 \%$ trypsin solution and incubated at $37^{\circ} \mathrm{C}$ for $3-5 \mathrm{~min}$. To release single cells, the mixture was pipetted several times with a $1 \mathrm{ml}$ pipette; a soybean inhibitor was added to neutralize trypsin and centrifugation was carried out (1,200 rpm, 5min and RT). The resulting pellet was rinsed with MCDB 153 medium (Sigma-Aldrich, Czech Republic) and the cell suspension placed in a cultivation flask for up to $72 \mathrm{~h}\left(2 \times 10^{5} \mathrm{cells} / \mathrm{ml}, 37^{\circ} \mathrm{C}, 5 \% \mathrm{CO}_{2}\right)$. The cell mixtures were maintained in growth medium with added $100 \mu \mathrm{g} / \mathrm{ml}$ geneticin for up to 5 days to remove contaminating keratinocytes and fibroblasts. Melanocyte identity was then confirmed using S-100 and anti-cytokeratin antibodies. The cultivation medium for melanocytes contained the melanocyte-growth supplement HMGS (Thermo Fisher Scientific, Czech Republic). The melanocyte growth medium was changed up to three times a week and $80 \%$ confluence was reached after approximately 12 days. Cultivation of the melanocytes was then carried out as described above.

\section{Cell lines}

Melanoma cell line Bowes (ATCC, No. CRL - 9607, Manassas, VA, USA) and SK-Mel-28 (ATCC, No. HTB72, Manassas, VA, USA) were cultivated in DMEM (Sigma-Aldrich) with $10 \%$ fetal bovine serum (Gibco, Prague, Czech Republic), $100 \mathrm{U} / \mathrm{ml}$ penicillin, and $100 \mu \mathrm{g} / \mathrm{ml}$ streptomycin. Cultures were kept in an incubator at $37^{\circ} \mathrm{C}$ and $5 \% \mathrm{CO}_{2}$ atmosphere and were passaged two times a week using $0.05 \%$ trypsin/EDTA upon reaching $90 \%$ confluence. Only mycoplasma-free cells were used for the experiments.

\section{Chemicals}

Zinc sulfate $\left(\mathrm{ZnSO}_{4} \cdot 7 \mathrm{H}_{2} \mathrm{O}\right.$ ) (Sigma-Aldrich, Czech Republic) was dissolved in a serum-free medium, sterilized by ultrafiltration, and stored until use as a stock solution of $1 \mathrm{M}$ in a refrigerator $\left(4^{\circ} \mathrm{C}\right)$. The cells were treated with a range of zinc sulfate concentrations of for up to $72 \mathrm{~h}$.

The dyes JC-1, acridine orange 10-nonyl bromide (NAO), Newport Green ${ }^{\mathrm{TM}}$ DCF diacetate, MitoSOX ${ }^{\mathrm{TM}}$ Red reagent, DQ-Green BSA and MitoTracker Green FM were acquired from Molecular Probes, Inc. (Eugene, U.S.A.). Triton-X; BrdU; monodansylcadaverine (MDC); 4',6-diamidino-2-phenylindole (DAPI) and Bafilomycin A1 were obtained from Sigma-Aldrich (St. Louis, MO, USA). Monoclonal and polyclonal antibodies were purchased from Cell Signaling Technology, Inc. (Danvers, MA, USA), secondary antibodies from Alexis Corporation (Lausen, Switzerland) and Dako (Glostrup, Denmark). All other chemicals were of the highest analytical grade.

\section{Proliferation assay}

The rate of DNA synthesis in the treated and control MEL cells, which is indicative of active cell cycling (proliferation), was estimated by measuring bromodeoxyuridine (BrdU) incorporation into the growing DNA strands. The MEL cells were seeded in black 96-well microtiter plates, with the first column of wells left blank. The cells were allowed to settle overnight at $37^{\circ} \mathrm{C}$ and in $5 \% \mathrm{CO}_{2}$. Subsequently, the cells were exposed to $\mathrm{Zn}$ at various concentrations for $72 \mathrm{~h}$. Before the end of incubation, BrdU was added $(10 \mu \mathrm{M}$ final concentration, Sigma-Aldrich, Prague, Czech Republic) to each well; at the end of the incubation period the medium was aspirated, and the cells were fixed (30 min, RT) and labeled with anti-BrdU. After incubation (60 min, RT) and three washing cycles, luminol substrate was added and chemiluminescence was measured using the multiplate reader TECAN SpectraFluor Plus (TECAN Austria GmbH, Grödig, Austria). For all measurements, integration time was $1000 \mathrm{~ms}$ and gain 130. The results were expressed in relative fluorescence units.

\section{Intracellular Zn concentrations}

Total and free intracellular $\mathrm{Zn}$ content in the MEL cells was determined as we have described previously [15]. In brief, the cultures were harvested by trypsinization (0.25 \% trypsin, Sigma-Aldrich, Prague, Czech Republic) and rinsed three times with cold phosphate buffered saline (PBS), with each rinsing followed by centrifugation for 5 min at 1,500 rpm (JOUAN MR 22, Trigon, Prague, Czech Republic) at room temperature (RT). The cells were dissolved in $0.35 \mathrm{ml} 0.8 \%$ nitric acid and assayed for $\mathrm{Zn}$ with the inductively coupled plasma emission spectrometer MSD 5972 (Agilent Technologies, Waldbronn, Germany). Prior to analysis, 


\section{Cellular Physiology Cell Physiol Biochem 2017;43:1-16 \begin{tabular}{ll|l} 
DOI: 10.1159/000480306 & O 2017 The Author(s). Published by S. Karger AG, Basel \\
www.karger.com/cpb
\end{tabular} \\ Rudolf/Rudolf: Intracellular Zinc Enhances the Activity of Human Melanocytes}

aliquots of the cell samples were assayed for protein content using a BCA assay (Bicinchoninic acid kit for protein determination, Sigma-Aldrich, Prague, Czech Republic). Changes in total intracellular $\mathrm{Zn}$ content were expressed as a percentage of control.

For the purpose determining the free intracellular $\mathrm{Zn}$ content, the cells grown in black-bottom 96-well plates were incubated with Newport Green diacetate ( $5 \mu \mathrm{mol}$ in PBS, dark, $30 \mathrm{~min}$ at $\left.37^{\circ} \mathrm{C}\right)$. Fluorescence intensity was determined by the multiplate reader TECAN SpectraFluor Plus (TECAN Austria GmbH, Grödig, Austria) at 485 and $535 \mathrm{~nm}$ respectively with stable integration time $1000 \mathrm{~ms}$ and gain 150 . The results in relative light units (RLU) were obtained from the raw data minus reagent blank, with changes expressed as a percentage of controls.

\section{Cell proliferation signaling}

The Zn-treated cells and control MEL cultures grown in 96-well microtiter plates were rinsed in PBS at individual time intervals, fixed in $4 \%$ paraformaldehyde, and permeabilized with cold methanol/Triton-X in $5 \%$ BSA. For the detection of individual proteins, the cells were then incubated with the following primary antibodies: anti-AKT1 1:100, anti-AKT2 1:100, anti-AKT3 1:100, anti-CYCD 1:100, anti-c-MYC 1:100, antiERK1/2 1:100, anti-p38 1:50, anti-p53 1:100, anti-p21 1:100, anti-p16 1:50 and anti-PTEN 1:50 at $4^{\circ} \mathrm{C}$ for 24h. After washing with cold PBS $\left(5 \mathrm{~min}, 25^{\circ} \mathrm{C}\right)$, FITC-conjugated goat anti-rabbit or anti-mouse (1:100) antibody was added for $1 \mathrm{~h}$ at $4^{\circ} \mathrm{C}$. The samples were then rinsed in PBS, counterstained with DAPI and the fluorescence was analyzed using the Cell Scoring module of MetaXpress ${ }^{\circledR}$ Image Acquisition and Analysis Software.

\section{Mitochondrial biogenesis}

The MEL cultures were seeded in 96-well microtiter plates and allowed to grow overnight at $37^{\circ} \mathrm{C}$. After treatment with Zn, the cells were rinsed in PBS and stained with MitoTracker Green FM (100 nM, $\left.30 \mathrm{~min}, 37^{\circ} \mathrm{C}\right)$ or $\mathrm{NAO}\left(2.5 \mu \mathrm{M}, 30 \mathrm{~min}, 37^{\circ} \mathrm{C}\right)$ and Hoechst $33528\left(10 \mathrm{nM}, 30 \mathrm{~min}, 37^{\circ} \mathrm{C}\right)$. Following rinsing with warm cultivation medium, mitochondrial mass in individual cells was assessed using the Cell Scoring module of MetaXpress ${ }^{\circledast}$ Image Acquisition and Analysis Software. In addition, as factors positively regulating mitochondrial biogenesis the expression of NRF2 and TFAM was determined by immunoblotting.

\section{Mitochondrial transmembrane potential $(\Delta \psi m)$ analysis}

The MEL cultures grown in cytospin chambers exposed to $\mathrm{Zn}$ were rinsed in warm medium and stained with cationic JC-1 dye $\left(10 \mu \mathrm{g} / \mathrm{ml}, 15 \mathrm{~min}, 37^{\circ} \mathrm{C}\right)$. This dye accumulates in mitochondria in a potential-dependent manner, indicated by a fluorescence emission shift from green to red. Mitochondrial depolarization due to a change in $\Delta \psi \mathrm{m}$ is indicated by a decrease in the red/green fluorescence intensity ratio, which reflects concentration dependent formation of red fluorescent J-aggregates. Thus following rinsing with warm medium, changes in $\Delta \psi \mathrm{m}$ in at least 1,000 cells were assessed under the fluorescence microscope Nikon Eclipse E 400 (Nikon, Prague, Czech Republic) (TRITC and FITC-specific filters); this microscope is equipped with the digital color matrix camera COOL 1300 (VDS, Vosskúhler, Germany). Photographs were taken using the software NIS Elements AR 3.20 and subsequently morphometrically analyzed. Results were expressed as percentage of cells with given $\Delta \psi \mathrm{m}$.

\section{Production of superoxide radical}

The generation of mitochondrial superoxide in Zn-treated melanocytes MEL was monitored by the MitoSOX ${ }^{\mathrm{TM}}$ Red reagent as recommended by manufacturer. Cells grown in cytospin chambers were exposed to $\mathrm{Zn}$, rinsed with warm medium and then co-incubated with MitoSOX $\mathrm{X}^{\mathrm{TM}}$ Red solution $\left(5 \mu \mathrm{M}, 20 \mathrm{~min}, 3^{\circ} \mathrm{C}\right)$ and MitoTracker Green FM solution ( $\left.100 \mathrm{nM}, 20 \mathrm{~min}, 37^{\circ} \mathrm{C}\right)$. After rinsing with warm medium and mounting, positivity (red signal) for mitochondrial superoxide was detected with the fluorescence microscope Nikon Eclipse E 400 (Nikon, Prague, Czech Republic) (TRITC and FITC-specific filters) equipped with a digital color matrix camera COOL 1300 (VDS, Vosskúhler, Germany). Photographs were taken using NIS Elements AR 3.20 software and subsequently morphometrically analyzed. Results were expressed as percentage of controls.

\section{Isolation of lysosomes}

The Zn-exposed and control MEL cells were harvested by trypsinization. The lysosomal compartments were subsequently isolated with the help of the lysosomal isolation kit LYSISO1 (Sigma-Aldrich, St. Louis, 


\section{Cellular Physiology Cell Physiol Biochem 2017;43:1-16 \begin{tabular}{l|l} 
DOI: 10.1159/000480306 & and Biochemistry \\
Published online: August 24, 2017 & $\begin{array}{l}\text { O 2017 The Author(s). Published by S. Karger AG, Basel } \\
\text { www.karger.com/cpb }\end{array}$ \\
\cline { 2 - 3 }
\end{tabular} \\ Rudolf/Rudolf: Intracellular Zinc Enhances the Activity of Human Melanocytes}

MO, USA) based on the manufacturer's recommendations. The harvested cells were centrifuged (500 $\mathrm{g} / 5 \mathrm{~min}$ ), resuspended in extraction buffer and homogenized by 10 cycles of a tuberculin syringe stroking on ice. Parallel control of cell destruction using a Trypan blue assay was carried out. Next, the nuclear compartment was removed by centrifugation at $20,000 \mathrm{~g} / 20 \mathrm{~min}$. The pellet containing lysosomes was resuspended in extraction buffer and again centrifuged at 20,000 g/60 min. Altogether, six individual fractions were collected, with each assayed for acid phosphatase activity (colorimetric acid phosphatase activity kit, Sigma-Aldrich, St. Louis, MO, USA), with correlation to protein concentration and Lamp-1 protein expression by immunoblotting.

\section{Zn content in lysosomes}

The MEL cells were grown in cultivation flasks in standard laboratory conditions. The cells were then exposed to external $100 \mu \mathrm{M} \mathrm{Zn}$ alone or together with the lysosomal $\mathrm{H}+$ inhibitor Bafilomycin $(1 \mu \mathrm{M})$. At individual time intervals, each lysosomal compartment was isolated using the lysosomal isolation kit LYSISO1. The obtained fractions positive for acid phosphatase activity (together 3) were pooled. Changes in $\mathrm{Zn}$ content of the pooled lysosomal fractions were then determined by inductively coupled plasma emission spectrometry as described above. Results were expressed as percentage of controls.

Lysosomal proteolytic activity assay

The cultured melanocytes (MEL) grown in 96-well plates were at $1 \mathrm{~h}$ before analysis exposed to $10 \mu \mathrm{M}$ DQ-Green BSA. They were then rinsed in warm cultivation medium, with fluorescence resulting from DQGreen BSA cleavage in the functional lysosomes determined by the multiplate reader TECAN SpectraFluor Plus (TECAN Austria GmbH, Grödig, Austria). Results were expressed as a time-dependent increase in fluorescence in arbitrary units.

Autophagy assays

Autophagy in the Zn-exposed melanocytes (MEL) was measured by the autofluorescent chemical MDC, which preferentially accumulates in autophagic vacuoles due to specific interactions with membrane lipids, resulting in a shift in MDC-specific fluorescence. The control and Zn-treated cells in 96-well plates with a transparent bottom were incubated with $50 \mu \mathrm{M}$ MDC in DMSO for $15 \mathrm{~min}$ at $37^{\circ} \mathrm{C}$ in the dark. After incubation, the wells were thoroughly rinsed twice in PBS, with MDC-positive signals quantified using a SpectrafluorPlus (TECAN Austria GmbH, Grödig, Austria) at $390 \mathrm{~nm}$ (excitation) and $455 \mathrm{~nm}$ (emission). Results are shown as a fold increase in MDC-specific fluorescence relative to the untreated cells. Independently, the expression of the autophagy markers BECLIN-1, p62 and LC3B in the control and treated cell cultures was determined by immunoblotting (see below).

Preparation of cell lysates and immunoblotting

The Zn-treated and control MEL cells were harvested with trypsin, washed with PBS and centrifuged (2000 rpm, $5 \mathrm{~min}, 4^{\circ} \mathrm{C}$ ). Each resulting pellet was used for preparation of whole cell lysates, with the cells resuspended in $5 \mathrm{ml}$ of an ice-cold lysis buffer $(137 \mathrm{mM} \mathrm{NaCl}, 10 \%$ glycerol, $1 \% \mathrm{n}$-octyl- $\beta$-Dglucopyranoside, $50 \mathrm{mM} \mathrm{NaF}, 20 \mathrm{mM}$ Tris, $1 \mathrm{mM}$ sodium orthovanadate and Complete TMMini) and stored at $-20^{\circ} \mathrm{C}$ until further use. The cell lysates were boiled for $5 \mathrm{~min} / 95^{\circ} \mathrm{C}$ in SDS sample buffer (Tris- $\mathrm{HCl} \mathrm{pH}$ 6.81, 2-mercaptoethanol, $10 \%$ glycerol, SDS, $0.1 \%$ bromphenol blue), and thereafter they were loaded onto a $12 \%$ SDS/polyacrylamide gel. Each lysate contained an equal amount of protein (30 $\mu \mathrm{g})$, as determined by the BCA assay. After electrophoresis, the proteins were transferred to a PVDF membrane $(100 \mathrm{~V}, 60$ $\mathrm{min})$ and incubated at $25^{\circ} \mathrm{C}$ for $1.5 \mathrm{~h}$ with a solution containing $5 \%$ nonfat dry milk, $10 \mathrm{mM}$ Tris- $\mathrm{HCl}(\mathrm{pH}$ 8.0), $150 \mathrm{mM}$ sodium chloride, and $0.1 \%$ Tween 20 (TBST). The membranes were incubated with primary antibodies (anti-NRF2, 1:750; anti-TFAM, 1:500; anti-COX IV, 1:1000; anti-LC3B, 1:750; anti-p62, 1: 750; anti-BECLIN-1, 1:500 and anti- $\beta$-ACTIN, 1:750) at $4^{\circ} \mathrm{C}$ overnight, followed by five 6 min washes in TBST. The blots were then incubated with secondary peroxidase-conjugated antibodies $\left(1: 1000,1 \mathrm{~h}, 25^{\circ} \mathrm{C}\right)$, washed with TBST, and the signal developed with a chemiluminescence (ECL) detection kit (Boehringer MannheimRoche, Basel, Switzerland).

Statistics

Statistical analysis was carried out with the statistical program GraphPad Prism (GraphPad Software version 6.0, Inc. San Diego, U.S.A.). We used a one-way Anova test with Dunnett's post test for multiple comparisons. Results were compared with control samples, with means considered significant at $\mathrm{P}<0.05$. 


\section{\begin{tabular}{ll} 
Cellular Physiology & Cell Physiol Biochem 2017;43:1-16 \\
\hline DOI: 10.1159/000480306 0 2017 The Author(s). Published by S. Karger AG, Basel
\end{tabular}

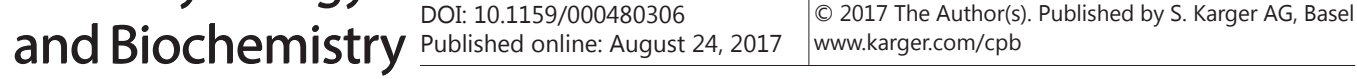 \\ Rudolf/Rudolf: Intracellular Zinc Enhances the Activity of Human Melanocytes}

\section{Results}

Proliferation and $\mathrm{Zn}$ content in isolated human melanocytes and melanoma cells

Human skin samples were obtained from 15 healthy adults ( 8 men and 7 women, age 1940 years), with samples from 10 adults resulting in successful human melanocyte isolation and cultivation. Altogether, melanocytes from 4 men (MEL1-4) and 6 women (MEL5-10) were used for the initial screening assays. Firstly, their proliferation rate was determined over a 72 $\mathrm{h}$ time period. Our results show that the melanocytes of all the obtained samples presented a similar proliferative activity, one which was significantly lower than in the model malignant melanoma cell lines Bowes and SK-Mel-28 (Fig. 1A). Measurements of total as well as free Zn levels further indicated a stable Zn content in all the analyzed samples irrespective of their origin and not dramatically different from the control melanoma cell lines (Fig. 1B and C). For subsequent studies two representative melanocyte cultivations designated MEL3 and MEL7 were used.

Chronic exposure to non-toxic $\mathrm{Zn}$ leads to increased intracellular accumulation in melanocytes and melanoma cells

The addition of extracellular $\mathrm{Zn}$ to cultivation media induced concentration-dependent elevation in the proliferative activity of both human melanocytes MEL3 and MEL7 at the treatment interval of $72 \mathrm{~h}$. While a slight increase was observed after 10 to $50 \mu \mathrm{M} \mathrm{Zn}$, a more significant increase occurred after a supplementation of $100 \mu \mathrm{M} Z \mathrm{Zn}$. Conversely, with the same treatment interval, Zn concentrations of $200 \mu \mathrm{M}$ and higher had an opposite effect (Fig.

Fig. 1. The proliferation and zinc content of human dermal melanocytes MEL and melanoma cells. (A) Isolated melanocytes from subjects 1-10 (designated MEL-MEL10) and human melanocyte cell lines Bowes and SK-Mel-28 were cultivated, and at given time intervals the chemiluminescent quantitation of DNA synthesis by an ELISA BrdU kit assay was measured as described in the section Materials and methods. Values represent means \pm SD of at least three experiments. $\mathrm{P}<0.05 *$ Significantly higher than cultures at the beginning of treatment, \# Significantly higher than isolated melanocytes at the same treatment interval with a one way-Anova test and Dunnett's post test for multiple comparisons. (B) Total zinc (Zn) content in primary human melanocytes MEL1-10 and melanoma cells Bowes and SK-Mel-28 during 72 h. Zn content was determined by absorption spectrometry as described in the section Materials and methods. (C) Free Zn content in primary human melanocytes MEL1-10 and melanoma cells Bowes and SK-Mel-28 at $72 \mathrm{~h}$ as determined by microfluorometry of the Zn-specific dye Newport Green diacetate in 96-well plates (Materials and methods). Values represent means \pm SD of at least three experiments.
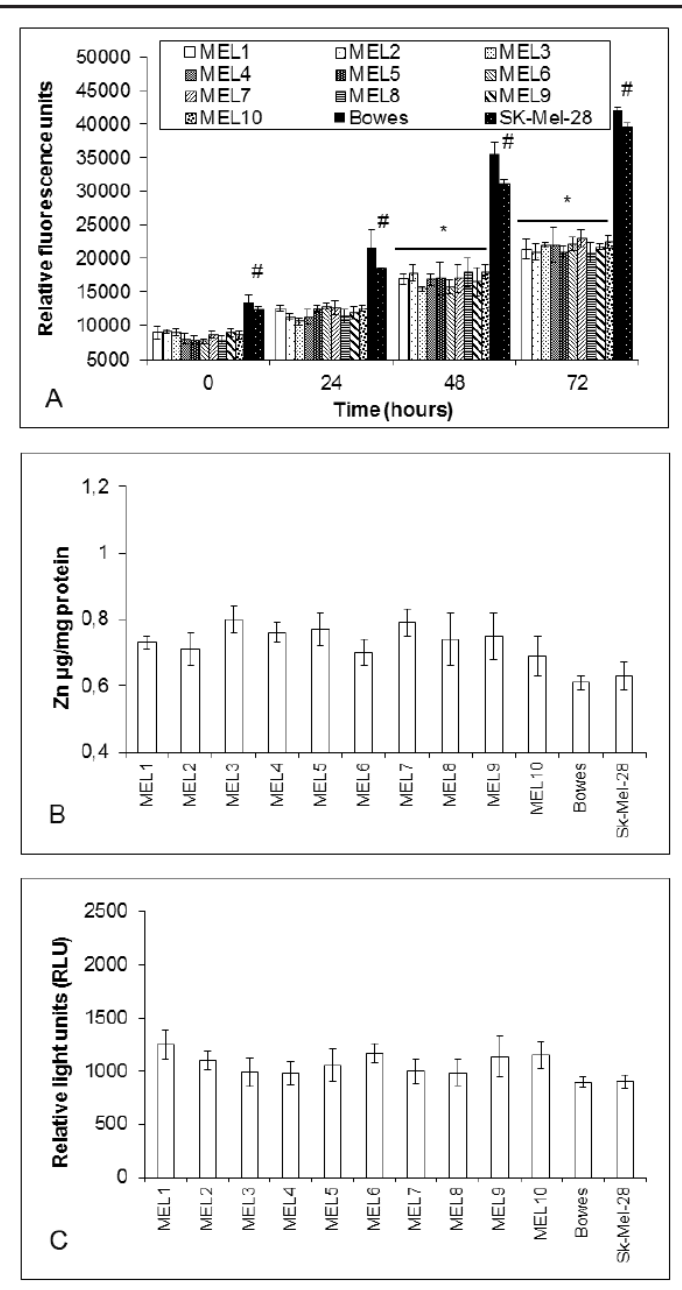




Fig. 2. The effect of externally added zinc sulfate $(\mathrm{Zn})$ on the proliferation and zinc content of primary human melanocytes MEL3 and MEL7 and melanoma cells Bowes and SK-Mel-28 during 72 h. Cells were exposed to $\mathrm{Zn}$ in medium and (A and B) proliferation was determined at given time intervals via the chemiluminescent quantitation of DNA synthesis by an ELISA BrdU kit assay as described in the section Materials and methods. Values represent means \pm SD of at least three experiments. $\mathrm{P}<0.05$. Significantly lower than control at the same treatment interval, \# Significantly higher than control at the same treatment interval with a one way-Anova test and Dunnett's post test for multiple comparisons. (C and D) Total Zn content and ( $\mathrm{E}$ and F) free $\mathrm{Zn}$ content were determined using absorption spectrometry and microfluorimetry as described in the section Materials and methods. Results represent means \pm SD of five experiments $\mathrm{P}<0.05$ * Significantly higher than control at the same treatment interval, \# Significantly lower than control at the same treatment interval with a one way-Anova test and Dunnett's post test for multiple comparisons.

2A). Melanoma cells proved to be more sensitive to external $\mathrm{Zn}$, e.g. concentrations of 100 $\mu \mathrm{M}$ or more led to decreased proliferation, with some positive effect on their proliferation observed at only $50 \mu \mathrm{M} Z \mathrm{Zn}$ (Fig. 2B). The proliferation-associated effects of supplemented Zn on human melanocytes and melanoma cells were paralleled with a concentration-dependent increase in total intracellular Zn content. The rate of buildup of total $\mathrm{Zn}$ content was strictly concentration-dependent (with the exception of the highest concentration of added $\mathrm{Zn}$ ). On the other hand, intracellular free $\mathrm{Zn}$ concentrations became significantly increased only upon exposure to higher Zn concentrations, which had differing effects on melanocyte proliferation (Fig. 2A and E). In the case of the melanoma cells, a similar trend was observed, although intracellular free Zn elevations never significantly increased (Fig. 2F). Owing to the acquired results, for subsequent experiments a $100 \mu \mathrm{M}$ Zn external concentration was used in the case of the melanocytes, while $50 \mu \mathrm{M} \mathrm{Zn}$ was employed in the melanoma cells.

Increases in intracellular Zn are associated with enhanced proliferative signaling in both melanocytes and melanoma cells

In order to further specify the extent of the molecular changes associated with Zndependent enhanced melanocyte and melanoma proliferation, the expression of selected 




Fig. 3. Effect of external zinc sulfate (Zn) on AKT1, AKT2, AKT3, CYCD, c-MYC, ERK1/2, p38, p53, p16, p21 and PTEN expression in primary human melanocytes MEL3 (A) and MEL7 (B) and melanoma cells Bowes

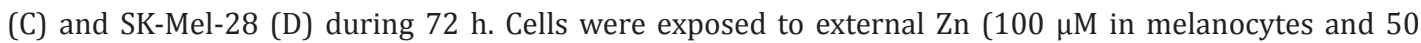
$\mu \mathrm{M}$ in melanoma cells), fixed, permeabilized and after incubation with particular antibody; corresponding fluorescence was measured by the Cell Scoring module of MetaXpress ${ }^{\circledR}$ Image Acquisition and Analysis Software. Results represent means \pm SD of at least three experiments. $\mathrm{P}<0.05 *$ Significantly higher than control at the same treatment interval with a one way-Anova test and Dunnett's post test for multiple comparisons.

proliferation-specific genes was evaluated using high content analysis. Our obtained data show that in the spectrum of evaluated proteins and a time interval of $72 \mathrm{~h}$ exposure to 100 $\mu \mathrm{M} \mathrm{Zn,} \mathrm{the} \mathrm{expressions} \mathrm{of} \mathrm{cyclin} \mathrm{D1} \mathrm{(CYCD),} \mathrm{c-MYC,} \mathrm{AKT3} \mathrm{and} \mathrm{ERK1/2} \mathrm{were} \mathrm{significantly}$ increased, while those of p53, AKT1, AKT2 and p38 reached only a slight (i.e. insignificant) elevation. On the other hand, the expressions of p21, p16 and PTEN remained at basal levels or were reduced (Fig. $3 \mathrm{~A}$ and B). In the melanoma cells, $50 \mu \mathrm{M} \mathrm{Zn}$ produced a significant change only in the expressions of ERK1/2 and AKT3 (Fig. 3C and D).

Externally added Zn stabilizes $\Delta \psi m$ and stimulates mitochondrial mass as well as ATP and ROS production in melanocytes but not in melanoma cells

Given the importance of mitochondria as a target of intracellular Zn, mitochondrial status and performance in the Zn-supplemented melanocytes and melanoma cells were next evaluated. Firstly, the effect of $\mathrm{Zn}$ supplementation on mitochondrial biogenesis (mass) was monitored using two independent mitochondrial stains - NAO and/or Mitotracker Green FM. During the first $24 \mathrm{~h}$ of treatment, the intensity of the fluorescent signals corresponding to cellular mitochondria remained the same irrespective of $\mathrm{Zn}$ supplementation. Nevertheless, compared to the untreated cultures, beginning at $48 \mathrm{~h}$ of treatment fluorescent intensity significantly grew in the Zn-exposed MEL3 melanocytes and at a $72 \mathrm{~h}$ interval also in the MEL7 cells, signifying Zn-dependent elevation in mitochondrial biogenesis. A similar trend was observed in the cultures using both stains (Fig. 4A and B). In parallel with these changes, Zn supplementation increased the expression of transcription factors NRF2 and TFAM which drive the transcription of key mitochondrial enzymes and mitochondrial DNA (Fig. 4C). Mitochondrial performance was subsequently assessed by measuring changes in $\Delta \psi \mathrm{m}$ using the specific cationic dye JC-1, which shows changed fluorescence upon accumulation 


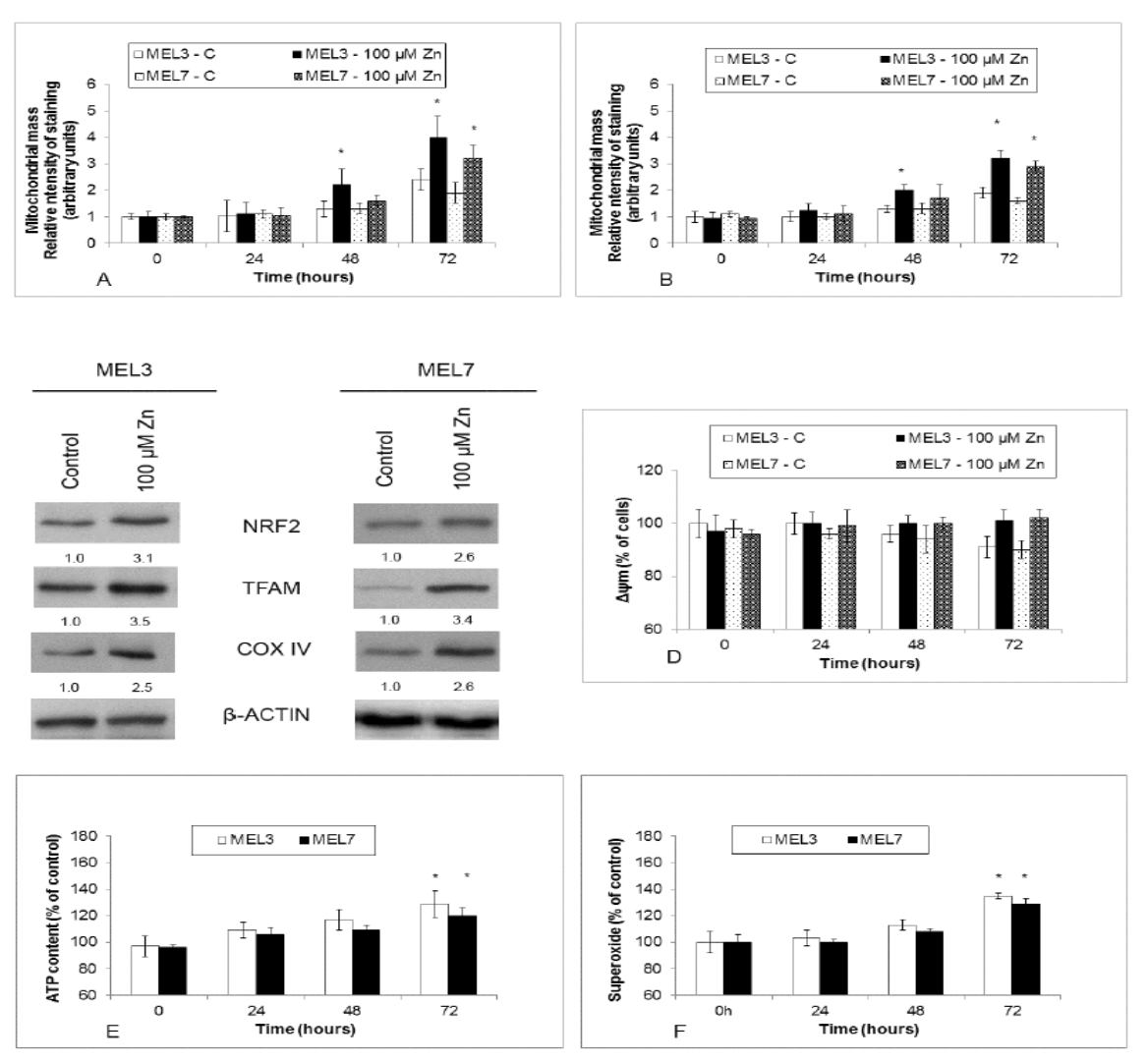

Fig. 4. Effect of external $100 \mu \mathrm{M}$ zinc sulfate (Zn) on mitochondrial mass, mitochondrial membrane potential $(\Delta \psi \mathrm{m})$, ATP and ROS productions in primary human melanocytes MEL3 and MEL7 during $72 \mathrm{~h}$. Cells were exposed to $\mathrm{Zn}$ and changes in mitochondrial biogenesis were visualized by MitoTracker Green FM (A) or acridine orange 10-nonyl bromide (NAO) (B) (Materials and methods). The expressions of transcription factors NRF2, TFAM and mitochondrial COX IV (C) were evaluated by immunoblotting as described in the section Materials and methods. The loading was normalized to $\beta$-actin and quantitative analysis of the bands was carried out by GelQuant Ver 2.7 software (DNR Bio-Imaging Systems, Jerusalem, Israel) (Materials and methods section). Results are shown of one typical experiment out of at least three. $\Delta \psi m$ dynamics were determined by JC-1 (D) (Materials and methods). ATP production (E) as well as generation of superoxide (F) were assayed as described in the section Materials and methods. Data represent the mean \pm S.D. of three independent experiments. $\mathrm{P}<0.05$ * Significantly higher than the beginning of treatment with the same concentration with a one way-Anova test and Dunnett's post test for multiple comparisons.

in functional or non-functional mitochondria. Both melanocyte cultures maintained in the presence of external Zn kept their $\Delta \psi \mathrm{m}$ at constant levels, which at later treatment intervals even became slightly elevated. Conversely, in the control cultures, $\Delta \psi \mathrm{m}$ gradually decreased in time, although this decrease was not statistically significant (Fig. 4D). Measurements of ATP content as well as production of superoxide further showed that the addition of Zn to the melanocytes induced a significant increase in both parameters at $72 \mathrm{~h}$ of treatment (Fig. $4 \mathrm{E}$ and F). In both employed melanoma cell lines, the addition of $50 \mu \mathrm{M} \mathrm{Zn}$ significantly changed neither mitochondrial biogenesis nor performance (Fig. 5).

\section{Zn enters into lysosomes}

Relative changes in the $\mathrm{Zn}$ content of lysosomes of the Zn-exposed melanocytes and melanoma cells were determined by spectrometry in individual cellular fractions in time. The obtained data show that $\mathrm{Zn}$ content in the lysosomes increased in a time-dependent manner, with the first significant elevation noted at $48 \mathrm{~h}$ of treatment in both the MEL3 
Fig. 5. Effect of external $50 \mu \mathrm{M}$ zinc sulfate (Zn) on mitochondrial mass, mitochondrial membrane potential $(\Delta \psi \mathrm{m})$, ATP and ROS productions in melanoma cells Bowes and SKMel-28 during $72 \mathrm{~h}$. Cells were exposed to $\mathrm{Zn}$ and changes in mitochondrial biogenesis were visualized by MitoTracker Green FM (A) or acridine orange 10-nonyl bromide (NAO) (B) (Materials and methods). The expressions of transcription factors NRF2, TFAM and mitochondrial COX IV (C) were evaluated by immunoblotting as described in Materials and methods section. The loading was

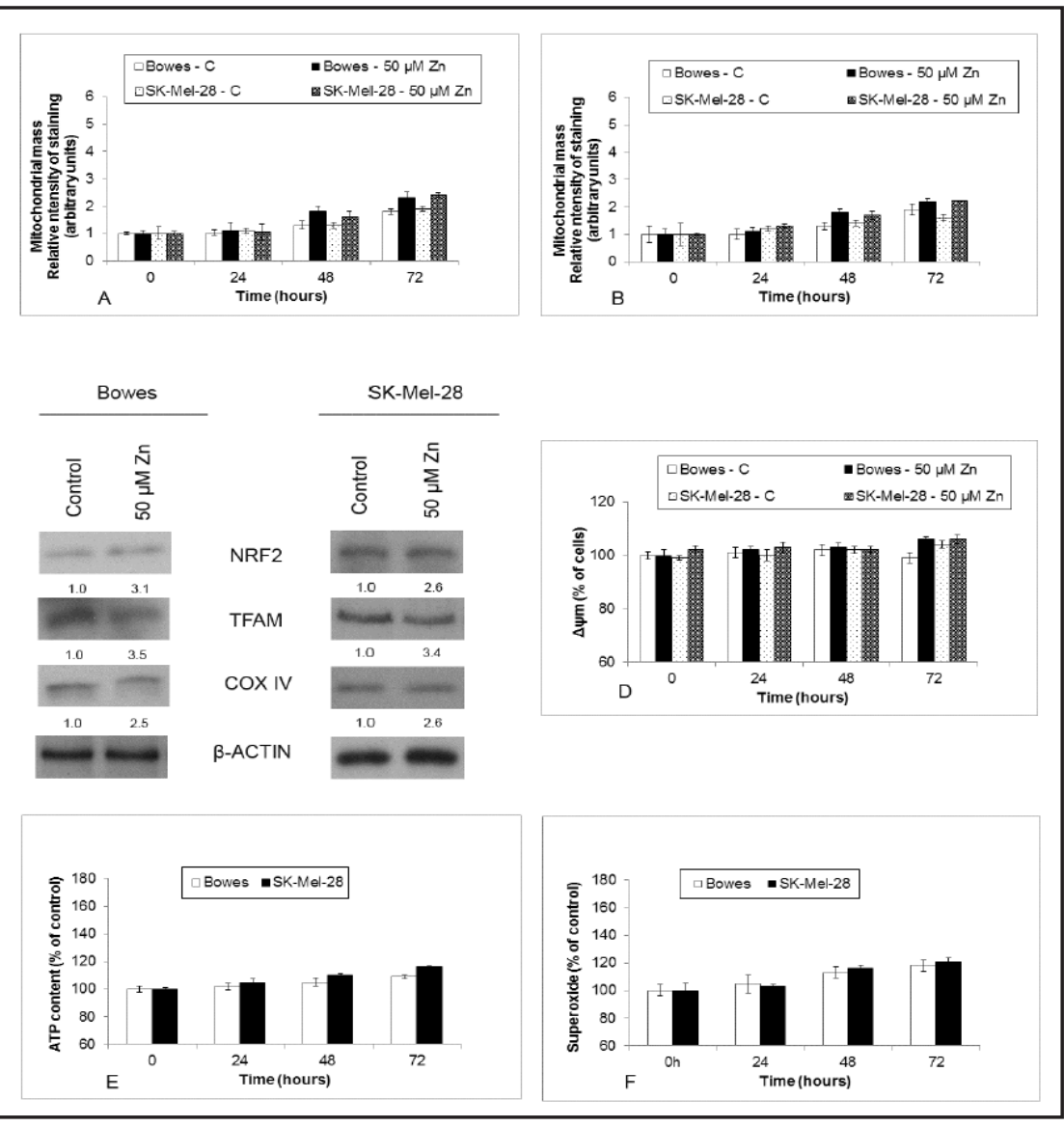
normalized to $\beta$-actin and quantitative analysis of the bands was carried out by GelQuant Ver 2.7 software (DNR Bio-Imaging Systems, Jerusalem, Israel) (Materials and methods section). Results are shown of one typical experiment out of at least three. $\Delta \psi \mathrm{m}$ dynamics was determined by JC-1 (D) (Materials and methods). ATP production (E) as well as generation of superoxide (F) were assayed as described in the section Materials and methods. Data represent the mean \pm S.D. of three independent experiments. $\mathrm{P}<0.05 *$ Significantly higher than the beginning of treatment with the same concentration with a one way-Anova test and Dunnett's post test for multiple comparisons.

and MEL7 cells (Fig. 6E). This marked subcellular partitioning of Zn into the lysosomes was further verified using a specific lysosomal $\mathrm{H}+$ pump inhibitor, which caused a rapid decrease in lysosomal Zn (Fig. 6F) and subsequent increase in cytoplasmic free Zn with corresponding features of cell stress in the exposed melanocytes (data not shown). On the other hand, Zn lysosomal content in the control melanoma cell lines Bowes and SK-Mel-28 treated with 50 $\mu \mathrm{M}$ Zn significantly changed at $72 \mathrm{~h}$ of exposure and in one cell line only (Fig. 7E and F).

Zn enhances endolysosomal pathway with a concomitant increase in autophagy in melanocytes but not in melanoma cells

The effects of $\mathrm{Zn}$ supplementation on the endolysosomal system in human melanocytes was determined by measuring the proteolytic activity of lysosomes. This activity gradually increased in cells exposed to external $\mathrm{Zn}$, reaching a significant elevation between 48 and $72 \mathrm{~h}$ of treatment. Also, MDC-specific fluorescence as well as the expressions of BECLIN-1, p62 and LC3B proteins strongly indicated a stimulated autophagic flux in the Zn-exposed melanocytes (Fig. 8A, C and E). On the other hand, in the melanoma cell lines, supplementation with $50 \mu \mathrm{M} \mathrm{Zn}$ failed to significantly enhance lysosomal activity nor autophagic flux as indicated by the lack of marked changes in the expression of key autophagic proteins and MDC-specific fluorescence (Fig. 8B, D and E). 


\section{Cellular Physiology Cell Physiol Biochem 2017;43:1-16

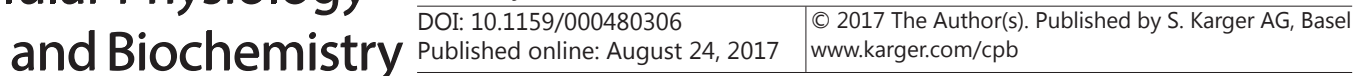

Fig. 6. Accumulation of zinc (Zn) in lysosomes primary human melanocytes MEL3 and MEL7. Cells were exposed to external $100 \mu \mathrm{M}$ Zn during $72 \mathrm{~h}$. Localization of $\mathrm{Zn}$ to the subcellular lysosomes of control cells and cells treated with Zn 100 during $72 \mathrm{~h}$ was investigated using cell fractionation and gradient centrifugation. Individual cell fractions were subjected to SDSPAGE, immunoblotted and probed with an antibody against Lamp-1 (lysosomal marker). The loading was normalized to $\beta$-actin and a quantitative analysis of the bands was carried out by

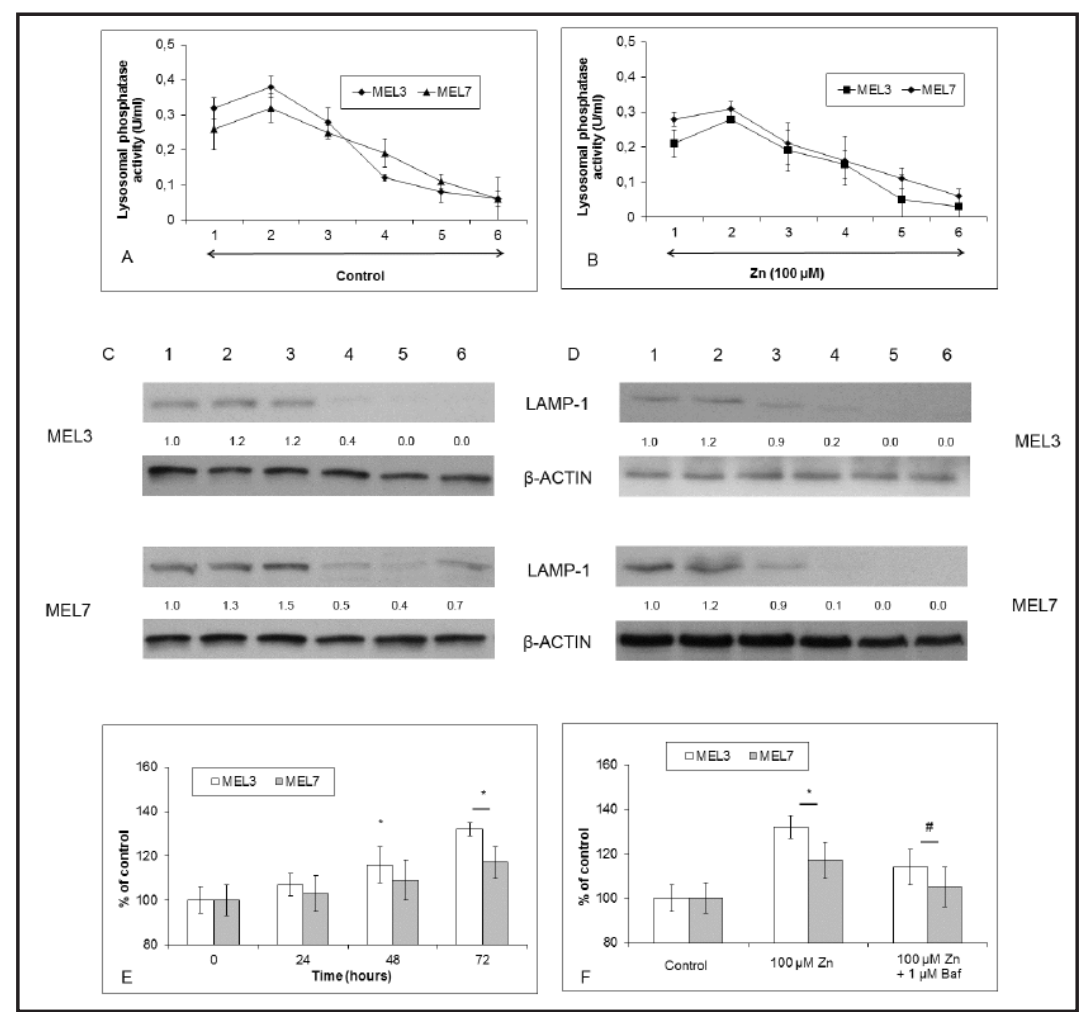

GelQuant Ver 2.7 software (DNR Bio-Imaging Systems, Jerusalem, Israel) (Materials and methods section). Results are shown of one typical experiment out of at least three. The fractions were also assayed for acid phosphatase activity: untreated cells (A), cells exposed to Zn 100 (B). Values represent means \pm SD of at least three independent experiments. Zn content in lysosomes of treated primary human melanocytes MEL3 and MEL7 at $72 \mathrm{~h}$ (E) was determined by absorption spectrometry as described in Materials and methods section. (F) Effect of lysosomal $\mathrm{H}+$ pump inhibitor Bafilomycin on $\mathrm{Zn}$ distribution in treated primary human melanocytes MEL3 and MEL7 at $72 \mathrm{~h}$. Cells were co-exposed to external Zn and $1 \mu \mathrm{M}$ Bafilomycin and Zn content in lysosomes was determined by absorption spectrometry as described in Materials and methods section. Results represent means \pm SD of five experiments. $\mathrm{P}<0.05{ }^{*}$ Significantly higher compared to the beginning of treatment (E) or compared to control (F) control at the same treatment interval, \# Significantly lower than Zn-exposure only with one way-Anova test and Dunnett's post test for multiple comparisons.

\section{Discussion}

Melanoma is the most dangerous form of skin cancer and also the one of the most scientifically challenging neoplasias due to its very complex genotypic, epigenetic and phenotypic background, resulting in the cancer's aggressive and not entirely predictable biological behavior. Although many constitutional as well as acquired risk factors have been defined for melanomagenesis, the entire range of mechanisms, factors and individual signals contributing to the malignant conversion of melanocytes have not been clearly elucidated to date.

The role of $\mathrm{Zn}$ in the development, survival and progression of melanoma remains unspecified to a great degree. However, the existing evidence, mostly indirect, suggests an impaired Zn content in melanoma patients [16-18] despite the fact that at present only limited knowledge exists about intracellular Zn management in skin melanocytes, the transformation of which contributes to $75 \%$ of cutaneous melanoma cases [19]. To address this question, we employed freshly isolated human melanocytes and exposed them to increasing external $\mathrm{Zn}$ concentrations to observe their biological responses and potential changes in their behavior. Unsurprisingly, we found that melanocytes exhibited a time- and dose-dependent response to externally added $\mathrm{Zn}$, with significant toxicity observed after exposure to $200 \mu \mathrm{M} \mathrm{Zn}$. This 


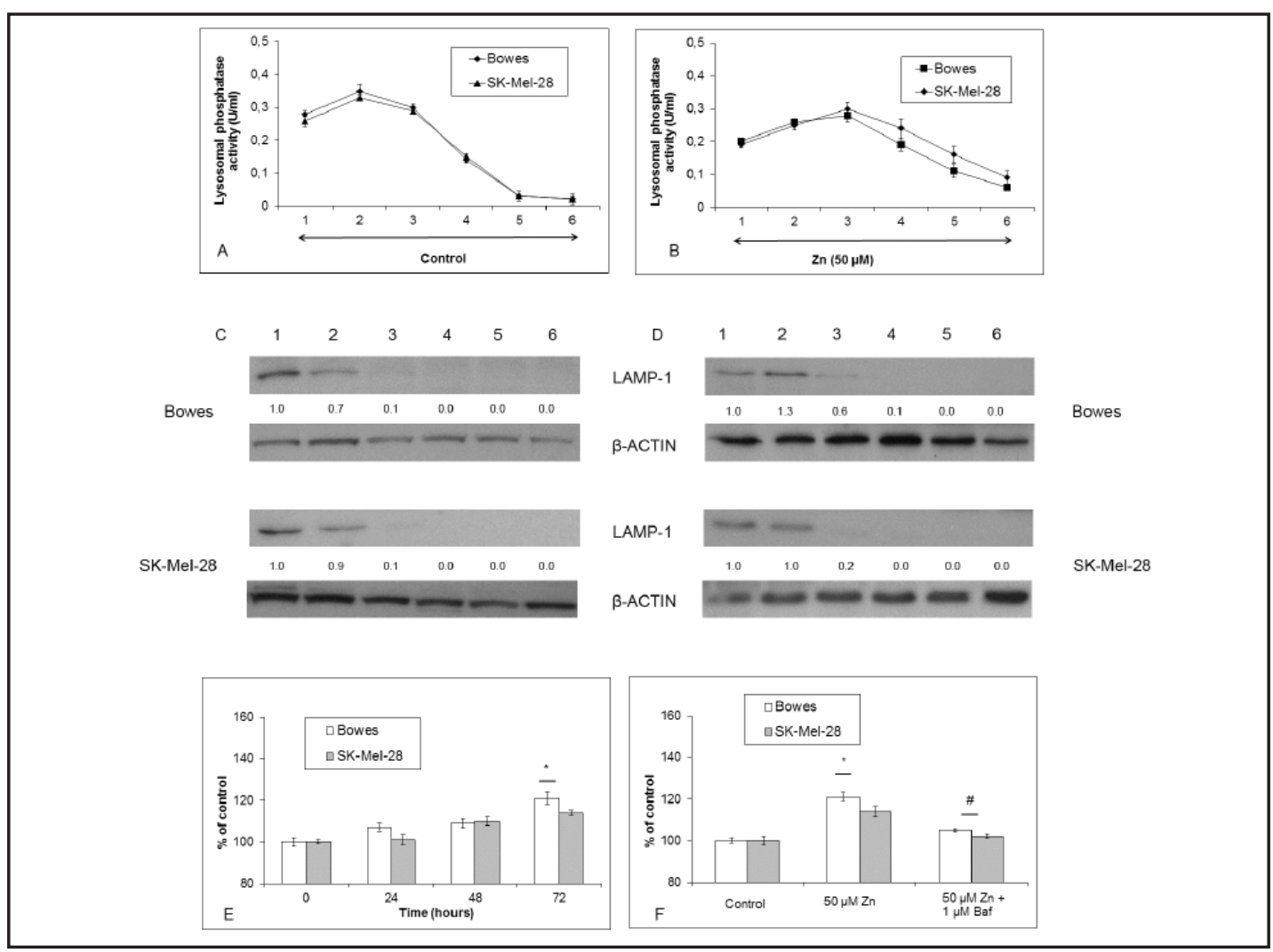

Fig. 7. Accumulation of zinc (Zn) in lysosomes of melanoma cells Bowes and SK-Mel-28. Cells were exposed to external $50 \mu \mathrm{M} Z \mathrm{Zn}$ during $72 \mathrm{~h}$. Localization of $\mathrm{Zn}$ to the subcellular lysosomes of control cells and cells treated with Zn during $72 \mathrm{~h}$ was investigated using cell fractionation and gradient centrifugation. Individual cell fractions were subjected to SDS-PAGE, immunoblotted and probed with antibody against Lamp-1 (lysosomal marker). The loading was normalized to $\beta$-actin and quantitative analysis of the bands was carried out by GelQuant Ver 2.7 software (DNR Bio-Imaging Systems, Jerusalem, Israel) (Materials and methods section). Results are shown of one typical experiment out of at least three. Also, the fractions were assayed for acid phosphatase activity: untreated cells (A), cells exposed to $\mathrm{Zn} 50$ (B). Values represent means \pm SD of at least three independent experiments. Zn content in the lysosomes of treated melanoma cells Bowes and SK-Mel-28 at $72 \mathrm{~h}$ (E) was determined by absorption spectrometry as described in the section Materials and methods. (F) Effect of lysosomal H+ pump inhibitor Bafilomycin on Zn distribution in treated melanoma cells Bowes and SK-Mel-28at 72 h. Cells were co-exposed to external Zn and $1 \mu \mathrm{M}$ Bafilomycin, with Zn content in the lysosomes determined by absorption spectrometry as described in the section Materials and methods. Results represent means \pm SD of five experiments. $\mathrm{P}<0.05 *$ Significantly higher compared to the beginning of treatment (E) or compared to control (F) at the same treatment interval, \# Significantly lower than Zn-exposure only with a one way-Anova test and Dunnett's post test for multiple comparisons.

toxicity was associated with an excessive intracellular accumulation of both bound as well as free $\mathrm{Zn}$, suggesting the depletion or gross impairment of Zn management mechanisms in the exposed cells. Interestingly in this context, compared to normal counterparts, malignant melanocytes appear to be more sensitive to external $\mathrm{Zn}$, as demonstrated in the employed melanoma cell lines Bowes and Sk-Mel-28 as well as in several published reports [20, 21], all of which seems to suggest that responsiveness to external $\mathrm{Zn}$ might change during melanomagenesis. This would require further studies.

Conversely, while low $\mathrm{Zn}$ concentrations showed no effect on the tested cells, within the same time framework, $\mathrm{Zn}$ at a concentration of $100 \mu \mathrm{M}$ had a significantly positive effect on the proliferation of all the tested melanocytes. This is in accordance with a recently reported effect of Zn on human epidermal keratinocytes HaCaT [22]. Melanocytes are KARGER 




Fig. 8. Lysosomal activity and autophagy in primary human melanocytes MEL3 and MEL7 and melanoma cells Bowes and SK-Mel-28. Cells were exposed to external $100 \mu \mathrm{M}$ Zn during $72 \mathrm{~h}$ (melanocytes) and to 50 $\mu \mathrm{M} \mathrm{Zn}$ during $72 \mathrm{~h}$ (melanoma cells) and (A, B) fluorescence emission of proteolyzed DQ-Green BSA reflecting lysosomal activity or (C, D) fluorescence emission from MDC-positive granules indicative of autophagy were determined spectrofluorimetrically as described in the section Materials and methods. Results represent means \pm SD of at least three independent experiments. $\mathrm{P}<0.05 *$ Significantly higher compared to the non-treated cells in the same time interval with one way-Anova test and Dunnett's post test for multiple comparisons. Changes in the expression of selected autophagy proteins - p62, BECLIN-1 and LC3B at $72 \mathrm{~h}$ in the same cells as determined by immunoblotting analysis (C). Cell lysates were subjected to SDS-PAGE, immunoblotted and probed with antibodies against the above-mentioned proteins as described in the section Materials and methods. The loading was normalized to $\beta$-actin and quantitative analysis of the bands was carried out by GelQuant Ver 2.7 software (DNR Bio-Imaging Systems, Jerusalem, Israel). Numbers in individual blot bands represent differences in band densities compared to non-treated cells. One typical result is shown for at least three independent experiments.

thought to form stable populations with a very low rate of proliferation which is associated with specific changes in cell cycle control elements [23]. Regarding the available evidence on the signaling pathways involved in the control of melanocyte proliferation and arrest, we assayed the expression of several key proteins. We found a $\mathrm{Zn}$-dependent increased abundance of ERK, CYCD, AKT3 and c-MYC proteins, a result which corresponds not only 


\section{Cellular Physiology Cell Physiol Biochem 2017;43:1-16 \begin{tabular}{ll|l} 
DOI: 10.1159/000480306 & Ond 2017 The Author(s). Published by S. Karger AG, Basel \\
www.karger.com/cpb
\end{tabular} \\ Rudolf/Rudolf: Intracellular Zinc Enhances the Activity of Human Melanocytes}

to our current understanding of melanocyte biology but also relates to certain events characteristic of melanoma cells [24, 25]. The exact mechanisms whereby $\mathrm{Zn}$ influences the proliferation of cells are likely diverse; increased calcium uptake [26], stimulated gene expression and changes in posttranslational proteins [27] have all been proposed to be involved. Nevertheless, it is important to remember that these effects are to a large degree dependent on the intracellular availability of free Zn. Here we have shown that the $100 \mu \mathrm{M}$ Zn concentration which stimulated melanocyte proliferation also increased intracellular free $\mathrm{Zn}$ stores. An excess of intracellular free $\mathrm{Zn}$ is dangerous for a cell, thus it must be contained either by buffering proteins such as metallothioneins [28] or sequestered to subcellular compartments including in the endoplasmic reticulum, Golgi body, mitochondria, lysosomes, or specifically in melanocytes melanosomes [29-31]. Since the role of some of these subcellular compartments in intracellular $\mathrm{Zn}$ management in melanocytes and melanoma is less known, in our subsequent work we focused firstly on mitochondria. We found that upon exposure to a non-toxic external $\mathrm{Zn}$ concentration which stimulates the proliferative activity of melanocytes, mitochondrial density as well as activity increased as evident from the stabilized membrane potential as well as elevated ATP and superoxide productions. The significantly elevated abundance of NRF2 and TFAM in the Zn-exposed melanocytes further underscores our observations since both transcription factors are important contributors to the sequence of events leading to the stimulated growth and division of pre-existing mitochondria [32]. Together with the present experiments, these data suggest at least that the mitochondrial compartment of melanocytes is an important target of increased intracellular Zn. Although generally positive for cells, such sustained mitochondrial activity may represent a challenge regarding the functional integrity of these same cells, particularly in circumstances in which this activity may contribute to the overwhelming of antioxidant defense systems and the induction of chronic oxidative stress. We have not focused on specific elements of ROS-dependent signaling here; nevertheless, it may be presumed that these elements were also involved, particularly in consideration of a similar study on epidermal keratinocytes [22]. In contrast, we did not observe similar mitochondria-stimulating effects of external Zn in melanoma cells, a finding which might be explained by the already existing high activity of this compartment or by the rapid buffering of free intracellular $\mathrm{Zn}$ levels, as is suggested at least somewhat by the less significant elevation of these levels in the exposed melanoma cells.

Recently it has been published that Zn may accumulate in lysosomes, and upon unregulated release it stimulates autophagy and cell injury [33]. Further studies then indicated that lysosomes and their networks might represent a special detoxification mechanism for transition metal toxicity [30]. Our current findings concur with this view, but also indicate the likely involvement of melanosomes in these circumstances. Melanosomes are lysosome-related organelles originating from the endosomal system. It has been postulated that in melanocytes, melanosomes represent an important reservoir for essential trace metals, including Zn [31]. Our analyses of Zn-rich lysosomal fractions in the Zn-exposed melanocytes (but not in the melanoma cells) revealed that some expressed higher tyrosinase activity (data not shown), thereby suggesting the increased presence of melanosomes. In addition, we provide evidence that when Zn entry to lysosomes/melanosomes is prevented via the specific inhibitor of the lysosomal $\mathrm{H}+$ pump, increased cytoplasmic $\mathrm{Zn}$ levels lead to cellular injury rather than being buffered in different compartments or by $\mathrm{Zn}$-sequestering proteins. Lysosomal/melanosomal $\mathrm{Zn}$ accumulation and the loss of acidification may impair functioning of these compartments and result in insufficient autophagy [34]. In contrast, we have observed the opposite effect; increased lysosomal/melanosomal activity and autophagy in Zn-enriched normal cells. This inconsistent observation may be explained for instance by the use of different biological models in particular studies (tumor cells versus normal cells). Also, one has to bear in mind the achieved magnitude of lysosomal $\mathrm{Zn}$ accumulation in the cells and the resulting changes in lysosomal luminal acidity which may differ in individual cases. Moreover, increased lysosomal/melanosomal activity could likely reflect the enhanced Zn secretion. Nevertheless, another very interesting aspect concerning these observations is 


\section{Cellular Physiology Cell Physiol Biochem 2017;43:1-16 \begin{tabular}{ll|l} 
DOI: 10.1159/000480306 24,2017 & $\begin{array}{l}\text { O } 2017 \text { The Author(s). Published by S. Karger AG, Basel } \\
\text { www.karger.com/cpb }\end{array}$
\end{tabular} \\ Rudolf/Rudolf: Intracellular Zinc Enhances the Activity of Human Melanocytes}

that malignant melanoma cells have been found to have upregulated endolysosomal circuitry which fosters melanoma progression [35]. In this context, the increased intracellular $\mathrm{Zn}$ content by which the endolysosomal pathway and associated autophagy are chronically stimulated may represent a potentially critical factor in the maintenance of the long-term melanocyte stability or propensity to melanomagenesis.

In summary, high concentrations of external $\mathrm{Zn}$ lead to a massive increase in free as well as bound intracellular $\mathrm{Zn}$, resulting in the induced injury of human dermal melanocytes. On the other hand, melanoma cells show a much higher sensitivity to external Zn. Moderate $\mathrm{Zn}$ concentrations still increase intracellular Zn stores, though with a positive effect on cell growth and proliferation accompanied by the upregulated expression of AKT3, ERK1/2, c-MYC and CYCD proteins. In addition, Zn-enriched melanocytes induce mitochondrial biogenesis with a stabilized $\Delta \psi \mathrm{m}$ as well as a concomitant elevation in ATP and superoxide production. Moreover, $\mathrm{Zn}$ enters the lysosomes and melanosomes which are stimulated in conjunction with the process of autophagy. This unique Zn-dependent stimulation of melanocytes and in particular the enhancement of their mitochondrial as well as lysosomal/ melanosomal activities could well prove potentially important in tracing the sequence of events occurring in the process of melanomagenesis.

\section{Acknowledgements}

This work was supported by the program PROGRESS Q40 01.

\section{Disclosure Statement}

The authors declare no conflict of interest regarding the publication of this paper.

\section{References}

1 Beyersmann D, Haase H: Functions of zinc in signaling, proliferation and differentiation of mammalian cells. Biometals 2001;14:331-341.

- MacDonald RS: The role of zinc in growth and cell proliferation. J Nutr 2000;130:1500S-1508.

- Ogawa Y, Kawamura T, Shimada S: Zinc and skin biology. Arch Biochem Biophys 2016;611:113-119.

4 Palmiter RD, Huang L: Efflux and compartmentalization of zinc by members of the SLC30 family of solute carriers. Pflugers Arch 2004;447:744-751.

5 Jeong J, Eide DJ: The SLC39 family of zinc transporters. Mol Aspects Med 2013;34:612-619.

6 Babula P, Masarik M, Adam V, Eckschlager T, Stiborova M, Trnkova L, Skutkova H, Provaznik I, Hubalek J, Kizek R: Mammalian metallothioneins: properties and functions. Metallomics 2012;4:739-750.

7 Prasad AS: Zinc and immunity. Mol Cell Biochem 1998;188:63-69.

-8 Truong-Tran AQ, Carter J, Ruffin R, Zalewski PD: New insights into the role of zinc in the respiratory epithelium. Immunol Cell Biol 2001;79:170-177.

-9 Tudor R, Zalewski PD, Ratnaike RN: Zinc in health and chronic disease. J Nutr Health Aging 2005; 9:45-51.

10 Frederickson CJ, Suh SW, Silva D, Thompson RB: Importance of zinc in the central nervous system: the zinccontaining neuron. J Nutr 2000;130:1471S-1483S.

11 Prasad AS, Kucuk 0: Zinc in cancer prevention. Cancer Metastasis Rev 2002;21:291-295.

12 Costello LC, Zou J, Franklin RB: In situ clinical evidence that zinc levels are decreased in breast invasive ductal carcinoma. Cancer Causes Control 2016;27:729-735.

-13 Gray-Schopfer V, Wellbrock C, Marais R: Melanoma biology and new targeted therapy. Nature 2007;445:851-857.

14 Hodis E, Watson IR, Kryukov GV, Arold ST, Imielinski M, Theurillat JP, Nickerson E, Auclair D, Li L, Place C, Dicara D, Ramos AH, Lawrence MS, Cibulskis K, Sivachenko A, Voet D, Saksena G, Stransky N, Onofrio RC, Winckler W, Ardlie K, Wagle N, Wargo J, Chong K, Morton DL, Stemke-Hale K, Chen G, Noble M, Meyerson M, Ladbury JE, Davies MA, Gershenwald JE, Wagner SN, Hoon DS, Schadendorf D, Lander ES, Gabriel SB, Getz G, Garraway LA, Chin L: A landscape of driver mutations in melanoma. Cell 2012;150:251-263. 


\section{Cellular Physiology Cell Physiol Biochem 2017;43:1-16 \begin{tabular}{ll|l} 
DOI: 10.1159/000480306 24,2017 & $\begin{array}{l}\text { O 2017 The Author(s). Published by S. Karger AG, Basel } \\
\text { www.karger.com/cpb }\end{array}$
\end{tabular} \\ Published online: August 24, 2017 .}

15 Rudolf E, Cervinka M: The role of intracellular zinc in chromium(VI)-induced oxidative stress, DNA damage and apoptosis. Chem Biol Interact 2006;162:212-227.

16 Bergomi M, Pellacani G, Vinceti M, Bassissi S, Malagoli C, Alber D, Sieri S, Vescovi L, Seidenari S, Vivoli R: Trace elements and melanoma. J Trace Elem Med Biol 2005;19:69-73.

17 Zamirska A, Matusiak L, Dziegiel P, Szybejko-Machaj G, Szepietowski JC: Expression of metallothioneins in cutaneous squamous cell carcinoma and actinic keratosis. Pathol Oncol Res 2012;18:849-855.

-18 Ros-Bullon MR, Sanchez-Pedreno P, Martinez-Liarte JH: Serum zinc levels are increased in melanoma patients. Melanoma Res 1998;8:273-277.

19 Bertolotto C: Melanoma: from melanocyte to genetic alterations and clinical options. Scientifica (Cairo) 2013;2013:635203.

-20 Provinciali M, Pierpaoli E, Bartozzi B, Bernardini G: Zinc Induces Apoptosis of Human Melanoma Cells, Increasing Reactive Oxygen Species, p53 and FAS Ligand. Anticancer Res 2015;35:5309-5316.

21 Borovansky J, Blasko M, Siracky J, Schothorst AA, Smit NP, Pavel S: Cytotoxic interactions of Zn2+ in vitro: melanoma cells are more susceptible than melanocytes. Melanoma Res 1997;7:449-453.

22 Emri E, Miko E, Bai P, Boros G, Nagy G, Rozsa D, Juhasz T, Hegedus C, Horkay I, Remenyik E, Emri G: Effects of non-toxic zinc exposure on human epidermal keratinocytes. Metallomics 2015;7:499-507.

23 Cichorek M, Wachulska M, Stasiewicz A, Tyminska A: Skin melanocytes: biology and development. Postepy Dermatol Alergol 2013;30:30-41.

24 Costin GE, Hearing VJ: Human skin pigmentation: melanocytes modulate skin color in response to stress. FASEB J 2007;21:976-994.

25 Madhunapantula SV, Mosca PJ, Robertson GP: The Akt signaling pathway: an emerging therapeutic target in malignant melanoma. Cancer Biol Ther 2011;12:1032-1049.

-26 O'Dell BL, Browning JD: Impaired calcium entry into cells is associated with pathological signs of zinc deficiency. Adv Nutr 2013;4:287-293.

27 Bellomo E, Hogstrand C, Maret W: Redox and zinc signalling pathways converging on protein tyrosine phosphatases. Free Radic Biol Med 2014;75:S9.

28 Maret W: Molecular aspects of human cellular zinc homeostasis: redox control of zinc potentials and zinc signals. Biometals 2009;22:149-157.

29 Lu Q, Haragopal H, Slepchenko KG, Stork C, Li YV: Intracellular zinc distribution in mitochondria, ER and the Golgi apparatus. Int J Physiol Pathophysiol Pharmacol 2016;8:35-43.

-30 Kukic I, Kelleher SL, Kiselyov K: Zn2+ efflux through lysosomal exocytosis prevents Zn2+-induced toxicity. J Cell Sci 2014;127:3094-3103.

31 Borovansky J: Zinc in pigmented cells and structures, interactions and possible roles. Sb Lek 1994;95:309320.

32 Bernard K, Logsdon NJ, Miguel V, Benavides GA, Zhang J, Carter AB, Darley-Usmar VM, Thannickal VJ: NADPH Oxidase 4 (Nox4) suppresses mitochondrial biogenesis and bioenergetics in lung fibroblasts via a nuclear factor erythroid-derived 2-like 2 (Nrf2)-dependent pathway. J Biol Chem 2017;292:3029-3038.

-33 Hwang JJ, Lee SJ, Kim TY, Cho JH, Koh JY: Zinc and 4-hydroxy-2-nonenal mediate lysosomal membrane permeabilization induced by H2O2 in cultured hippocampal neurons. J Neurosci 2008;28:3114-3122.

-34 Yamada D, Saiki S, Furuya N, Ishikawa K, Imamichi Y, Kambe T, Fujimura T, Ueno T, Koike M, Sumiyoshi K, Hattori N: Ethambutol neutralizes lysosomes and causes lysosomal zinc accumulation. Biochem Biophys Res Commun 2016;471:109-116.

-35 Alonso-Curbelo D, Riveiro-Falkenbach E, Perez-Guijarro E, Cifdaloz M, Karras P, Osterloh L, Megias D, Canon E, Calvo TG, Olmeda D, Gomez-Lopez G, Grana O, Sanchez-Arevalo Lobo VJ, Pisano DG, Wang HW, Ortiz-Romero P, Tormo D, Hoek K, Rodriguez-Peralto JL, Joyce JA, Soengas MS: RAB7 controls melanoma progression by exploiting a lineage-specific wiring of the endolysosomal pathway. Cancer Cell 2014;26:6176. 